\title{
Malignant ovarian tumors in patients 14 - 20 years, a 3 decades experience in a public hospital 1985 - 2015 San Borja Arriaran Hospital
}

Roberto Altamirano 1, Patricia Acosta1, Raul Larraguibel1, Luciano Rojas1, Matias Solari1, Eliecer Pincheira1, Omar Nazzal1, Eugenio Suarez ${ }^{1}$.

${ }^{1}$ Hospital San Borja Arriaran, Unidad de Ginecologia Oncológica, Universidad de Chile, Santiago, Chile.

\section{Objectives:}

Describe malignant ovarian tumors in patients 14 - 20 years, between 1985 - 2015 at San Borja Arriaran Hospital (HCSBA) in Santiago, Chile. HCSBA is a public institution that covers about $20 \%$ of the chilean capital population.

\section{Methods:}

Retrospective search in the gynecology oncology and pathology HCSBA units data bases of the following parameters; histology type and age of initial diagnostic. We found a total of 20 records of female patients with malignant ovarian tumors between 14-20 years, that were reviewed and analyzed by 3 members of our unit.

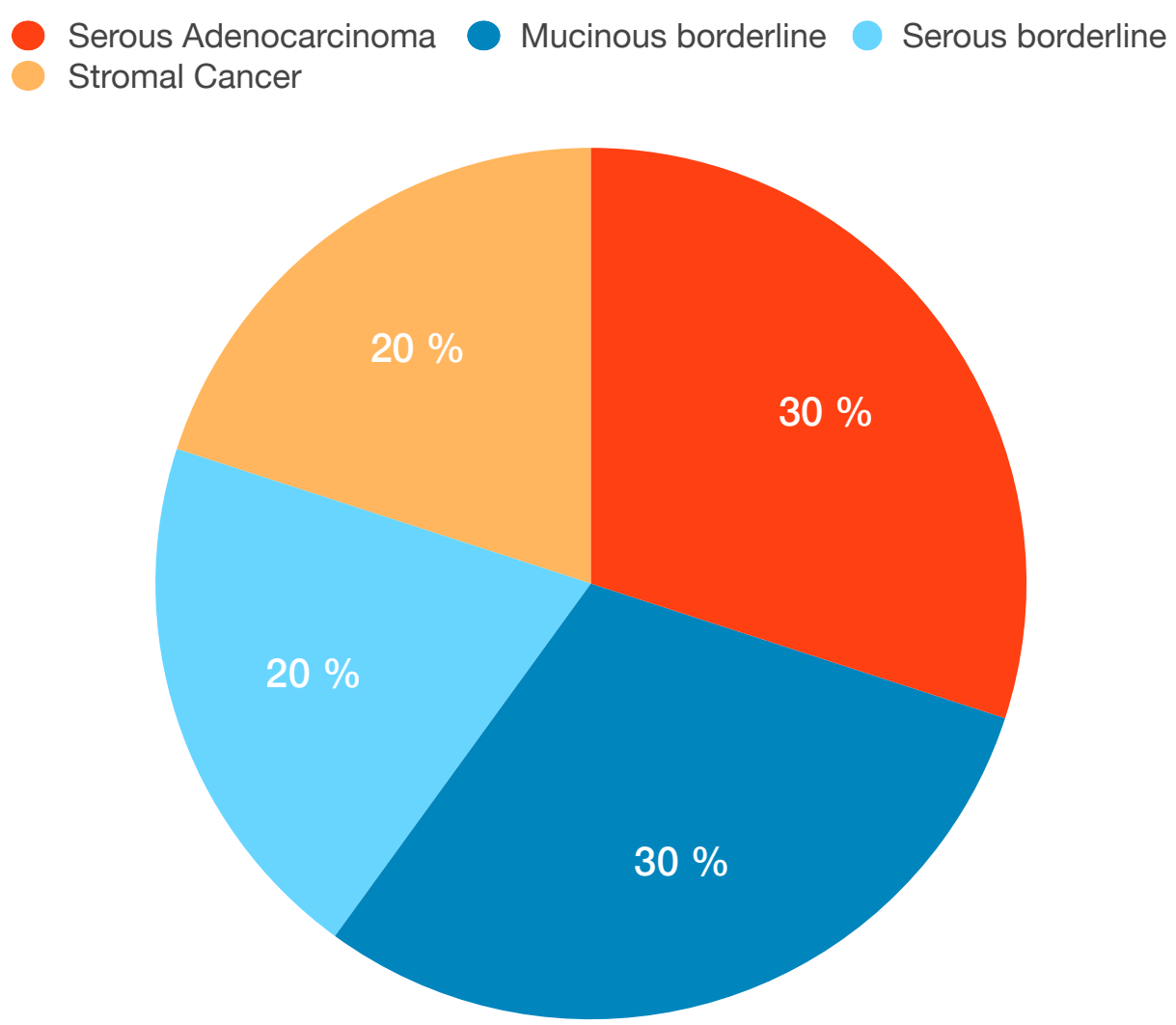

Ferlay, D, Bray, J, Steliarova-Foucher. F, Forman, E. Cancer Incidence in Five Continents, CI5plus. IARC Cancer BAse No. 9. Lyon Int. Agency Res. Cancer: 2017

\section{Results}

The most frequent histology was germinal tumors (50\%) followed by epithelial (40\%). The distribution for germinal tumor was: dysgerminoma (60\%) followed by yolk sac tumor (20\%), and immature teratoma (20\%).

The most common epithelial tumor was mutinous borderline (38\%) followed by serous adenocarcinoma (38\%) and serous borderline (24\%)

There were only 2 cases of stromal cancer. $85 \%$ of the tumors were early FIGO stage; $60 \%$ IA and $25 \%$ IC.

The median age of diagnostic was 17,5 years

Disgerminoma Immature teratoma Yolk sac tumor

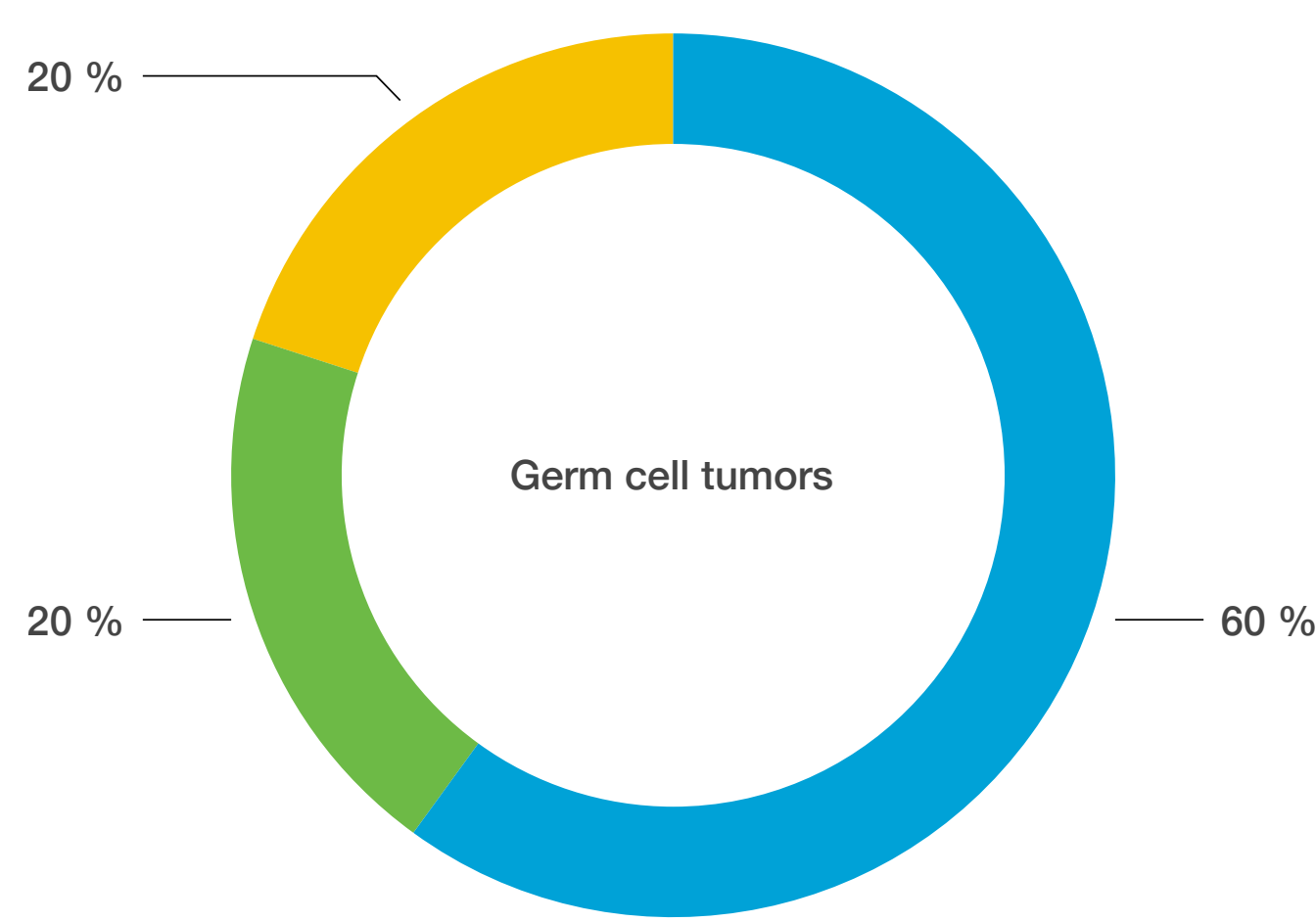

\section{Conclusions:}

Our findings were similar as those founded in the international literature in prevalence and age related incidence in tumors under 20 years. It is important to stablished histologic type and stage to plan a proper conservative surgery and medical treatment 